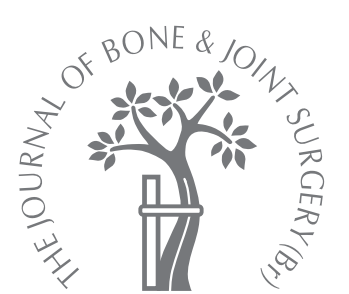

L. Klenerman

\title{
The evolution of the compartment syndrome since 1948 as recorded in the JBJS (B)
}

\author{
This paper describes how we came to understand the pathophysiology of Volkmann's \\ ischaemic contracture with references to relevant papers in this Journal, and the \\ investigation and management of acute compartment syndrome is briefly discussed.
}

At the time of the first issue publication of the Journal of Bone and Joint Surgery, Volkmann's ischaemic contracture was well recognised. In $1881,{ }^{1}$ Volkmann had suggested that paralysis and contracture came on simultaneously because of interruption of the blood supply to the muscles. He thought the most common cause was the application of tight bandages to the injured limb, usually the upper, but less frequently the lower. Attention had been drawn to the "soft tissue effusion" in an injured limb. In 1914, Murphy ${ }^{2}$ considered that this pressure obstructed the venous circulation and advocated, as a prophylactic procedure, splitting the deep fascia to relieve it: "This can be done with a tenotome.... the fascia on the antero-ulnar side of the forearm should be split for a distance of 3 to 6 inches subcutaneously".

In 1924, Paul Jepson, ${ }^{3}$ while working at the Mayo Foundation, was the first surgeon to reproduce ischaemic contracture in animals and to demonstrate that these contractures may be prevented by prompt surgical decompression. In 1928, Robert Jones ${ }^{4}$ stated that "It is necessary to fix in our minds that this distressing deformity may arise from pressure within the limb or without. It is generally a combination of both". During the first World War, unexplained contractures associated with arterial injuries were thought to be a result of arterial spasm. Leriche ${ }^{5}$ subsequently considered that this spasm was caused by an autonomic reflex arising in the damaged artery, causing occlusion of the main vessel and its collateral branches. Treatment was directed towards interrupting this reflex arc by sympathectomy, or arterial stripping. In 1940, Lloyd Griffiths, in a Hunterian lecture, ${ }^{6}$ again asserted that arterial spasm was the main cause of Volkmann's contracture. He dismissed all considerations of venous occlu- sion or subfascial haematoma, and he thought that tight splintage was merely contributory. This view was widely accepted. He argued that the first line of treatment for impending contracture should be a sympathetic block, and subsequently, if there was no improvement exploration of the artery was indicated. He elaborated on the management of arterial spasm in a paper entitled, "The management of acute circulatory failure in an injured limb" in $1948 .^{7}$

The first paper on ischaemic necrosis to appear in the British issue of the Journal was by Hughes "Ischaemic necrosis of the anterior tibial muscles due to fatigue". ${ }^{8} \mathrm{He}$ indicated that it was not well known that such necrosis could arise without injury, and that many cases were probably unrecognised. ${ }^{8}$ Ischaemia followed strenuous or unaccustomed exercise in two of his cases and he concluded that the most likely cause was spasm of the anterior tibial artery from muscle fatigue aggravated by increased tension within the anterior fascial compartment. He noted two previous reports of a relationship between exercise and circulatory disturbances of the anterior tibial muscles. ${ }^{8}$

However, Dr Edward Wilson who died with Captain Scott, in his last Antarctic Expedition, described in his diary that in the afternoon of a day's march of exceptional length (22 statute miles) over a difficult surface, the tibialis anterior muscle of his left leg became swollen and exceedingly painful and the overlying skin was red and oedematous. ${ }^{9}$ His symptoms seem to have continued for about three weeks. All these details gleaned from the diaries of Wilson and Scott correspond closely with the clinical picture of an anterior tibial compartment syndrome. Dr Wilson thus probably gave the first clinical account of this now commonly recognised condition. 
In 1956, Mavor ${ }^{10}$ described a professional footballer with symptoms of pain in the anterior compartment of both legs for two years. Both compartments were decompressed with relief of symptoms. Griffiths ${ }^{11}$ in an annotation was sceptical of the diagnosis in this patient as there was no evidence of pathology of the decompressed muscle and the symptoms of pain after exercise were vague. In a paper published in 1957, entitled "March gangrene", 12 three more cases following physical activity, such as football or marching, but without a history of trauma, were added. It was noted that during exercise a muscle may gain as much as $20 \%$ of its own weight by the accumulation of extracellular fluid. Early and extensive fasciotomy was recommended. The following year, in a description of observations at operation on three patients with limb injuries and vascular complications, Benjamin ${ }^{13}$ suggested that tension resulting from oedema in a fascial compartment might be an important aetiological factor in maintaining arterial spasm. It was proposed that the increased tension maintained the arterial spasm and the consequent ischaemia aggravated the oedema and the tension in the fascial compartment. Release of the tension by fascial decompression in these patients lead to relaxation of the artery and full recovery. The complex aetiopathology was slowly being unravelled. Griffiths, ${ }^{14}$ in an annotation wrote: "Benjamin may be right; further evidence will show. Let us, however, beware of attractive theories which may often be accepted because they cannot be rejected. Surgery has been led astray too often by just this fallacy".

In 1958, a review of 343 soundly united tibial fractures by Ellis, ${ }^{15}$ later to become Professor of Surgery at Westminster Hospital, London, recorded the limitation of ankle and/or foot movement in 21 patients $(6 \%)$, and one third of these had clinical evidence of ischaemic contracture. He suggested that unrecognised vascular damage or spasm may complicate even minor fractures, and the resulting ischaemia of muscle may produce sufficient scarring to restrict movement. ${ }^{15}$ In 1966 , Seddon ${ }^{16}$ reported 15 cases of Volkmann's ischaemia in the lower limb. He thought it was more common in adults than in children and that it occurred with sufficient frequency after injuries of the femur, knee and leg to warrant measures to prevent it. The first and most essential step was to recognise the early signs of ischaemic damage. Incision of the deep fascia might then save the threatened underlying muscle, though it may also be necessary to look for and evacuate a haematoma beneath the muscle. ${ }^{16}$

MacGowan ${ }^{17}$ in a paper on acute ischaemia complicating limb trauma wrote "Sometimes the toes or fingers may show no signs of circulatory inadequacy and indeed all peripheral pulses may be present yet the limb may be extremely swollen and in danger. Even when the skin circulation is normal, ischaemic necrosis may occur with subsequent Volkmann's contracture".

In 1979, Holden $^{18}$ in a paper based on a Hunterian lecture entitled, "The pathology and prevention of Volk- mann's ischaemic contracture," first clearly explained the deveopment of ischaemic contracture. He quoted Kinmonth, Simeone and Perlow who, in 1949, had demonstrated that it was impossible to induce arterial spasm by sympathetic stimulation, either directly or reflexly, and that it was impossible to relieve it by sympathetic interruption. ${ }^{18}$ He pointed out that with increased knowledge of closed arterial injuries following the Korean War, a direct blow or a traction injury to an artery might cause an incomplete tear of the vessel wall. An intimal tear allowed stripping of the intima, shearing off the entrance to collateral branches; the exposed area of the vessel provided a raw surface on which a thrombus would form, and as the thrombus extended, it blocked not only the main vessel but also the collateral branches. In addition, traction may induce an arterial injury which does not tear the vessel but simply stretches it and causes it to contract. If this is severe, the vessel will collapse and blood flow will cease. Such critical closure can only be diagnosed by exploring the vessel and increasing its diameter again by injecting a bolus of fluid through the narrow segment. If this fails to dilate the vessel, one is not dealing with a pure traction lesion, but with collapse of the vessel distal to an intimal tear.

Persistence of the ischaemia after injury caused by swelling of muscles and nerves is a result of these tissues being contained in an unyielding compartment. Because of the increased tissue pressure, the normal fluid exchange through capillaries in muscle is affected. There is anoxic damage to the capillary walls, plasma colloids leak out and the osmotic pressure decreases. Much more fluid leaves the capillaries than returns, which further increases the volume of the tissue fluids. As the pressure rises, the venous end of the capillary will become occluded, as will eventually the whole capillary, and even the arterioles. A stage will be reached where almost no fluid returns to the capillary. A vicious circle is established in the microcirculation. Only a prompt and generous fasciotomy will allow the tissues to swell without a dangerous rise of pressure.

In the same issue of the Journal, an editorial by Eadie $^{19} \mathrm{a}$ vascular surgeon, catagorically stated: "It cannot be stressed enough that arterial spasm in an ischaemic limb after trauma is always dangerous, but it is surprising how often this diagnosis is made and the condition left untreated for too long before attempts are made to repair the damaged artery. Whenever doubt exists, no harm comes from exploration of the artery preceded by arteriography if readily available".

When the mechanism of the development of compartment syndrome had been clarified, the clinical measurement of intracompartmental pressure was introduced. Mubarak et al, ${ }^{20}$ in 1975, were among the first to use these measurements for the diagnosis of an acute compartment syndrome. In 1984, Rorabeck ${ }^{21}$ described 18 patients with acute compartment syndrome below the knee. Preoperative tissue measurements were undertaken in all cases and the range was $28 \mathrm{mmHg}$ to $47 \mathrm{mmHg}{ }^{21}$ Allen et al ${ }^{22}$ 
reported their experience in 28 patients. The technique used was a slit catheter in conjunction with continuous infusion. Three of their patients required decompression and they concluded that if the pressure is above $50 \mathrm{mmHg}$ or higher than $40 \mathrm{mmHg}$ for more than six hours, fasciotomy is indicated. McQueen and Court-Brown ${ }^{23}$ prospectively studied 116 patients with tibial fractures who had continuous monitoring of the anterior tibial compartment for 24 hours. The use of a differential pressure of $30 \mathrm{mmHg}$ as a threshold for fasciotomy resulted in no missed cases. They recommended decompression if the difference between the intracompartmental pressure and the diastolic blood was less than 30 mmHg. ${ }^{23}$

Further progress in our understanding and management of compartment syndrome is covered in the review article, "Diagnosing acute compartment syndrome" in 2003. ${ }^{24}$

Fasciotomy is occasionally not indicated. It is best avoided when the muscle is already dead, a situation which invariably exists in acute muscle crush compartment syndrome, which follows injuries in trapped survivors after earthquakes, or in war casualties. Reis and Better ${ }^{25}$ from Israel, reported their experience over 35 years in 31 patients treated conservatively. With a conservative protocol, no case of closed crush injury developed life threatening sepsis and no urgent amputation was required. In their opinion, there is no place for prophylactic fasciotomy under these circumstances. A patient with a poor functional result following acute compartment syndrome in a crushed limb will subsequently require reconstructive procedures to improve function.

It is interesting to see how long it took to gain an understanding of the pathophysiology of compartment syndrome. The first recorded attempt to measure tissue fluid pressure (interstitial fluid pressure) using subcutaneous needle cannulation was reported in $1884 .{ }^{26}$ In 1896 , Starling ${ }^{27}$ had pointed out that under normal conditions, a state of near equilibrium exists at the capillary membrane, whereby the amount of fluid filtering outward through arterial capillaries equals the quantity of fluid that is returned to the circulation by reabsorption at the venous ends of the capillaries. It took approximately 70 years for this basic science to be adapted to orthopaedic practice and for attention to be focused on the microcirculation. This also shows the opportunities for the incremental increase in knowledge obtained by the publication of case reports and case series currently frowned upon by the emergence of evidencebased orthopaedics.

\section{References}

1. Volkmann RV. Die ischaemischen muskellahmungen und kontrackuren. Zentralb $F$ Chir 1881:8:80-1.

2. Murphy JB. Myositis. J Am Med Ass 1914;63:1249

3. Jepson PN. Ischaemic contracture: experimental study. Annals Surg 1926;84:785.

4. Jones R. Volkmann's ischaemic contracture with special reference to treatment. $\mathrm{Br}$ Med Journal 1928;2:639-42.

5. Leriche R. Surgery of the sympathetic system: indications and results. Annals Surg 1928;883:449-69.

6. Griffiths DL. Volkmann's ischaemic contracture. Br J Surg 1940;28:239-60

7. Griffiths DL. The management of acute circulatory failure in an injured limb. $J$ Bone Joint Surg [Br] 1948;30-B:280-9.

8. Hughes JR. Ischaemic necrosis of the anterior tibial muscles due to fatigue. $J$ Bone Joint Surg [Br] 1948;30-B:581-94

9. Freedman BJ. Edward Wilson of the Antarctic. Procs Royal Society of Med 1954; $47: 183-9$.

10. Mavor GE. The anterior tibial syndrome. J Bone Joint Surg [Br] 1956;38-B:513-17.

11. Griffiths DL. The anterior tibial syndrome: a chronic form? J Bone Joint Surg [Br] 1956;38-B:438-9.

12. Blandy JP, Fuller R. March gangrene: ischaemic myositis of the leg muscles from exercise. J Bone Joint Surg [Br] 1957;39-B:679-83.

13. Benjamin A. The relief of traumatic arterial spasm in threatened Volkmann's ischaemic contracture. J Bone Joint Surg [Br] 1957;39-B:711-13.

14. Griffiths DL. The maintenance of traumatic arterial spasm. J Bone and Joint Surg [Br] 1957;39-B:613.

15. Ellis H. Disabilities after tibial shaft fractures: with special reference to Volkmanns ischaemic contracture. J Bone Joint Surg [Br] 1958;40-B:190-6.

16. Seddon HJ. Volkmann's ischaemia in the lower limb. J Bone Joint Surg [Br] 1966;48-B:627-36.

17. MacGowan W. Acute ischaemia complicating limb trauma. J Bone Joint Surg [Br] 1968;50-B:472-81.

18. Holden CEA. The pathology and prevention of Volkmann's ischaemic contracture J Bone Joint Surg [Br] 1979;61-B:296-300.

19. Eadie DGA. Post-traumatic ischaemia. J Bone Joint Surg [Br] 1979;61-B:265-6.

20. Mubarak SJ, Hargens AR, Owen CA, Garetto LP, Akeson WH. The wick catheter technique for measurement of intramuscular pressure. J Bone Joint Surg $[\mathrm{Br}]$ 1976;58-A:1016-20.

21. Rorabeck CH. The treatment of compartment syndrome of the leg. J Bone Joint Surg [Br] 1984;66-B:93-7.

22. Allen MJ, Stirling AJ, Crawshaw CV, Barnes MR. Intra compartmental monitoring of leg injuries: an aid to management. J Bone Joint Surg [Br] 1985;67-B:53-7.

23. McQueen MM, Court-Brown CM. Compartment monitoring in tibial fractures. J Bone Joint Surg [Br] 1996;78-B:99-103.

24. Elliott KGB, Johnstone AJ. Diagnosing acute compartment syndrome. J Bone Joint Surg [Br] 2003;85-B:625-32.

25. Reis ND, Better OS. Mechanical muscle-crush injury and acute muscle-crush compartment syndrome. J Bone Joint Surg [Br] 2005;87-B:450-3.

26. Landerer AS. Die gewebspannung in ihrem einfluss auf die ortliche blutbewegung und lymphbewgung. Vogel, Leipzig 1884.

27. Starling EH. On the absorption of fluids from connective tissue spaces. J Physiology (London) 1896;19:312-26. 